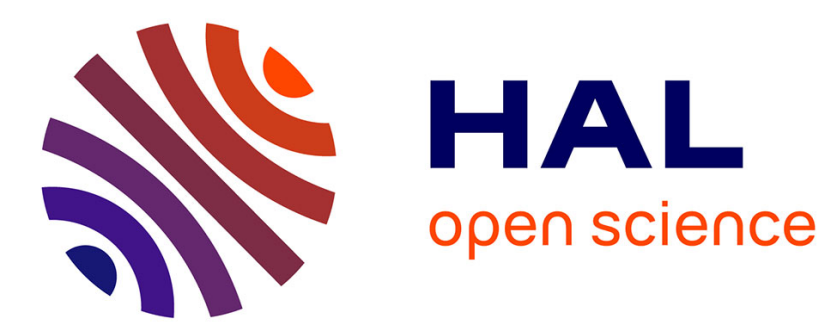

\title{
Experimental Design Approach to Development of a CVD ZrN Coating
}

\author{
W. Russell
}

\section{To cite this version:}

W. Russell. Experimental Design Approach to Development of a CVD ZrN Coating. Journal de Physique IV Proceedings, 1995, 05 (C5), pp.C5-127-C5-134. 10.1051/jphyscol:1995513 . jpa00253826

\section{HAL Id: jpa-00253826 https://hal.science/jpa-00253826}

Submitted on 1 Jan 1995

HAL is a multi-disciplinary open access archive for the deposit and dissemination of scientific research documents, whether they are published or not. The documents may come from teaching and research institutions in France or abroad, or from public or private research centers.
L'archive ouverte pluridisciplinaire HAL, est destinée au dépôt et à la diffusion de documents scientifiques de niveau recherche, publiés ou non, émanant des établissements d'enseignement et de recherche français ou étrangers, des laboratoires publics ou privés. 
JOURNAL DE PHYSIQUE IV

Colloque C5, supplément au Journal de Physique I, Volume 5, juin 1995

\title{
Experimental Design Approach to Development of a CVD ZrN Coating
}

W.C. Russell

Valenite, Inc., 1711 Thunderbird, Troy, MI, 48084, U.S.A.

\begin{abstract}
A design of experiments (DOE) approach has been used for the study of CVD ZrN coatings on cemented carbide substrates. DOE maximizes information gained from a set of experiments through statistical methods of design and analysis. A full factorial matrix of twenty experiments was designed using the variables (A) pressure, (B) temperature, (C) $\mathrm{H}_{2} / \mathrm{ZrCl}_{4}$ and (D) $\mathrm{N}_{2} / \mathrm{ZrCl}_{4}$. Pressure ranged from 100 to 300 torr, temperature from 900 to $1050^{\circ} \mathrm{C}, \mathrm{H}_{2} / \mathrm{ZrCl}$ from 20 to 60 and $\mathrm{N}_{2} / \mathrm{ZrCl}_{4}$ from 5 to 25 . The response for deposition rate is compared with theoretical prediction based on thermodynamic modeling of the system. A normal probability distribution was used to identify the variables that had a significant effect on deposition rate. These were found to be (B) temperature and (C) $\mathrm{H}_{2} / \mathrm{ZrCl}_{4}$. Interaction plots for (B) and (C) generated by the software clearly show this effect. These results are in agreement with the thermodynamic analysis and are similar to results for TiN coating. Other responses such as color, surface morphology, texture, adhesion and friction are reported.
\end{abstract}

\section{INTRODUCTION}

Zirconium Nitride, as a coating, has been produced by several different methods. In PVD form, $\mathrm{ZrN}$ is claimed to be considerably harder than TiN. On the Vickers scale it measures roughly 3100 while TiN measures 2300 [1]. Several manufacturers claim the PVD coating works well in cutting high-silicon aluminum, copper and copper alloys. ZrN films have also been produced by ion beam assisted deposition (IBAD) in the forms $\mathrm{ZrN}$ and $\mathrm{Zr}_{3} \mathrm{~N}_{4}$ [2]. These were designed for electronic applications but have also been tested on cutting tools. These coatings have a highly oriented (111) cubic structure. ZrN deposited by reactive triode ion plating were found to outperform TiN and TiAIN in turning at higher speeds $(\sim 55$ $\mathrm{m} / \mathrm{min}$.) [3] and the $\mathrm{ZrN}$ films were found to be more uniform. In testing of PVD coatings produced by ARE (activated reactive evaporation) and HRRS (high rate reactive sputtering) $\mathrm{ZrN}$ was found to have significantly better flank wear resistance than TiN and the same level of crater wear resistance. The only CVD ZrN has been produced by Krupp Widia and consisted of a sequence of TiN, TiCN and ZrN. The coating had applications in steel, cast steel, malleable cast iron and stainless steel. The overall perception seems to be that while $\mathrm{ZrN}$ would not replace TiN generally in the cutting tool marketplace, it could be a significant niche market coating.

In an initial study of the CVD of $\mathrm{ZrN}$, it was desired to derive as much information as possible from the set of experiments. Experimental design methods can give the user the most information per test. First, the parameters to be varied (temperature, pressure, etc.) and the responses to be monitored were identified. Then with the aid of software [4] a designed experimental matrix was developed with a randomized sequence of tests. Finally, statistical methods were used to analyze the responses, again with the aid of software. The text by Box, Hunter and Hunter [5] covers this approach thoroughly.

\section{EXPERLMENTAL DESIGN}

The CVD system contained a gas delivery panei, an end-feed hot-wall graphite reactor and an exhaust system comprising a vacuum pump and scrubber. $\mathrm{ZrCl}_{4}$ reactant was produced by means of a generator at elevated temperature containing zirconium metal through which $\mathrm{HCl}$ was passed. Only $\mathrm{ZrCl}_{4}$ was 
considered for this study along with process gases $\mathrm{H}_{2}$ and $\mathrm{N}_{2}$. Thermodynamic analysis of the generator reactions showed sub-chloride formation to be very small compared to $\mathrm{ZrCl}_{4}$.

\subsection{Design Matrix}

The basic CVD parameters were represented by four variables as follows:

Table I: DOE Variables and Ranges

\begin{tabular}{|c|c|c|c|c|}
\hline Variable & Parameter & Low & Mid. & High \\
\hline \hline A & Pressure & 100 torr & 200 & 300 \\
\hline B & Temperature & $900^{\circ} \mathrm{C}$ & 975 & 1050 \\
\hline C & $\mathrm{H}_{2} / \mathrm{ZrCl}$ & 20 & 40 & 60 \\
\hline D & $\mathrm{N}_{2} / \mathrm{ZrCl}_{4}$ & 5 & 15 & 25 \\
\hline
\end{tabular}

For each variable there was selected a low, middle and high value. For a full factorial representation including centerpoints, this results in a twenty experiment matrix as shown in Table II.

Table II: DOE Tests and Results

\begin{tabular}{|c|c|c|c|c|c|c|c|c|c|}
\hline Exp. & $\begin{array}{l}\text { Temp. } \\
\left({ }^{\circ} \mathrm{C}\right)\end{array}$ & $\begin{array}{l}\text { Press. } \\
\text { (torr) }\end{array}$ & $\mathrm{H}_{2} / \mathrm{ZrCl}_{4}$ & $\mathrm{~N}_{2} / \mathrm{ZrCl}_{4}$ & $\begin{array}{c}\text { Dep. Rate } \\
(\mu \mathrm{m} / \mathrm{hr})\end{array}$ & $\mathbf{L}^{*}$ & $a^{*}$ & $\mathbf{b}^{*}$ & Structure \\
\hline 1 & 975 & 200 & 40 & 15 & 1.88 & 47.4 & 2.1 & 33.9 & icosahedral \\
\hline 2 & 900 & 100 & 60 & 5 & 1.23 & 63.7 & 2.9 & 33.4 & icosahedral \\
\hline 3 & 900 & 100 & 20 & 5 & 1.55 & 57.6 & 3.4 & 40.4 & icosahedral \\
\hline 4 & 1050 & 100 & 60 & 5 & 1.74 & 73.7 & 3.6 & 33.6 & rounded \\
\hline 5 & 900 & 100 & 60 & 25 & 1.05 & 60.8 & 3.0 & 34.9 & icosahedral \\
\hline 6 & 975 & 200 & 40 & 15 & 1.06 & 62.8 & 2.4 & 33.3 & icosalhedral \\
\hline 7 & 1050 & 300 & 20 & 25 & 3.13 & 71.7 & 2.5 & 29.2 & rounded \\
\hline 8 & 975 & 200 & 40 & 15 & 1.86 & 56.9 & 3.3 & 31.2 & icosahedral \\
\hline 9 & 975 & 200 & 40 & 15 & 1.18 & 64.3 & 2.4 & 30.5 & icosahedral \\
\hline 10 & 1050 & 100 & 20 & 25 & 3.61 & 0 & 6.0 & 18.2 & fine \\
\hline 11 & 1050 & 300 & 20 & 5 & 4.30 & 58.2 & 0.8 & 23.2 & rounded \\
\hline 12 & 1050 & 100 & 20 & 5 & 3.88 & 66.0 & 4.2 & 33.1 & fine \\
\hline 13 & 900 & 300 & 60 & 25 & 0.79 & 15.2 & 19.8 & 72.2 & icosahedral \\
\hline 14 & 1050 & 100 & 60 & 25 & 2.06 & 66.1 & 3.1 & 29.9 & rounded \\
\hline 15 & 1050 & 300 & 60 & 5 & 3.10 & 10.2 & 11.3 & 30.4 & fine \\
\hline 16 & 900 & 100 & 20 & 25 & 1.12 & 57.0 & 2.1 & 26.4 & icosahedral \\
\hline 17 & 900 & 300 & 20 & 25 & 0.95 & 63.5 & 2.9 & 36.8 & icosahedral \\
\hline 18 & 900 & 300 & 60 & 5 & 0.37 & 72.7 & 2.1 & 28.9 & icosahedral \\
\hline 19 & 900 & 300 & 20 & 5 & 0.92 & 74.4 & 3.0 & 29.8 & icosahedral \\
\hline 20 & 1050 & 300 & 60 & 25 & 2.07 & 80.4 & 0.8 & 22.4 & rounded \\
\hline
\end{tabular}

\subsection{Response Variables}

The following response variables were measured from the matrix of experiments.

Appearance - A Gardner colorsphere was used to quantify color and reflectivity of the surface (Table I). There are three variables. Variable $a^{*}$ is a measure of color on a green to red scale. Variable $b^{*}$ is a measure on a blue to yellow scale and variable $L^{*}$ is a black to white scale. Each variable was entered as a response variable and the predicted trend analyzed.

Deposition Rate - Measured thickness can easily be converted into deposition rate and analyzed as a response variable. Measurements were made using the ball polish method (Table I).

Structure - Surface structure can be quantified through measurement of surface crystallite size and distribution. The crystallites could not be effectively isolated using image analysis techniques so a more qualitative classification system was used (Table I). 
Texture - Crystallographic orientation of the coatings can be measured using XRD. The texture coefficient, $\mathrm{TC}_{\mathrm{hkl}}$, is a measure of the intensity of $\mathrm{X}$-rays reflected from a certain crystallographic plane referenced to a standard intensity.

Adhesion - Adhesion is a critical property of any coating and was measured using a Revetest ${ }^{\mathrm{TM}}$ scratch tester [6-7]. A Jinearly increasing load was translated across a coating surface through the tip of a diamond stylus. A critical load, $\mathrm{L}_{\mathrm{c}}$, for adhesion can be determined by observing the acoustic response in conjunction with microscopic observation of the scratch track. Although the method is not strictly quantitative it does yield useful information about coating adhesion.

Friction and Surface Roughness - In a similar method to scratch testing, friction can be measured using the Revetest ${ }^{\mathrm{TM}}$ unit. Instead of measuring the acoustic response, the tangential force, $F_{t}$, can be directly measured. This contains information relating to friction.

\section{THERMODYNAMIC ANALYSIS}

Thermodynamic properties of the reactants are used in a free energy minimization scheme to predict stable species for a given temperature, pressure and infinite time to allow the system to come to equilibrium. However, in the real world only fast reactions approach the predicted equilibrium levels for dynamic systems. Diffusion or reaction kinetics often play a role in determining the degree of the reaction. Even in these cases thermodynamic reaction analysis is useful in determining driving forces for reactions and likely formed species. This information can be time saving in designing a desirable set of CVD parameters. Software, including a thermochemical database, was used to perform the equilibrium calculations [8]. There are many examples for CVD in the literature $[9,10]$. The fundamental reaction for this system is:

$$
\mathrm{ZrCl}_{\times}+\frac{1}{2} \mathrm{~N}_{2}+\frac{\mathrm{x}}{2} \mathrm{H}_{2} \rightarrow \mathrm{ZrN}+\mathrm{xHCl}
$$

As mentioned previously, sub-chlorides produced by the generator were predicted in very small quantities and only $\mathrm{ZrCl}_{4}$ was considered. Except for where a particular parameter was varied the set of conditions used in modeling was: pressure $=150$ torr, temperature $=700-1150^{\circ} \mathrm{C}, \mathrm{N}_{2}=0.392 \mathrm{~mole}, \mathrm{ZrCl}_{4}=0.014$ mole and $\mathrm{H}_{2}=0.593$ mole.

Figure la shows $\mathrm{ZrN}$ formation as a function of temperature and $\mathrm{ZrCl}_{4}$ concentration. $\mathrm{ZrN}$ increases regularly with increasing temperature and $\mathrm{ZrCl}_{4}$ concentration. The response to the other key reactant, nitrogen, is similar. The effect of pressure is predicted to be very small compared to temperature. Figure $\underline{1 b}$ shows the predicted $\mathrm{ZrN}$ response to temperature and $\mathrm{H}_{2}$ concentration. There is a stronger effect of $\mathrm{H}_{2}$ than of $\mathrm{ZrCl}_{4}$ and $\mathrm{N}_{2}$. Referring to equation (1), in the absence of hydrogen, $\mathrm{HCl}$ cannot form and chlorine must form $\mathrm{Cl}_{2}$ as a by-product. The presence of $\mathrm{H}_{2}$ significantly drops the free energy of reaction and thus $\mathrm{H}_{2}$ has a profound effect on the formation of $\mathrm{ZrN}$.

Modeling indicates that it is possible to form $\mathrm{ZrN}$ over a fairly wide range of conditions. In the furnace, it is necessary not to starve the reactions. This will ensure process stability and smooth responses to parameter changes. Pressure responses should also be smooth at levels normal for typical CVD processes (50-200 torr). Initial parameter ranges were set as shown in Table I based on this modeling.

\section{RESULTS AND ANALYSIS}

This section will address measurement and analysis of the properties or response variables, several for which the raw data is summarized in Table II.

\subsection{Deposition Rate}

Thickness measurements were made using a standard ball polishing method (Table II). A nomal probability distribution is a straight line with a positive slope. Any points deviating significantly from this 


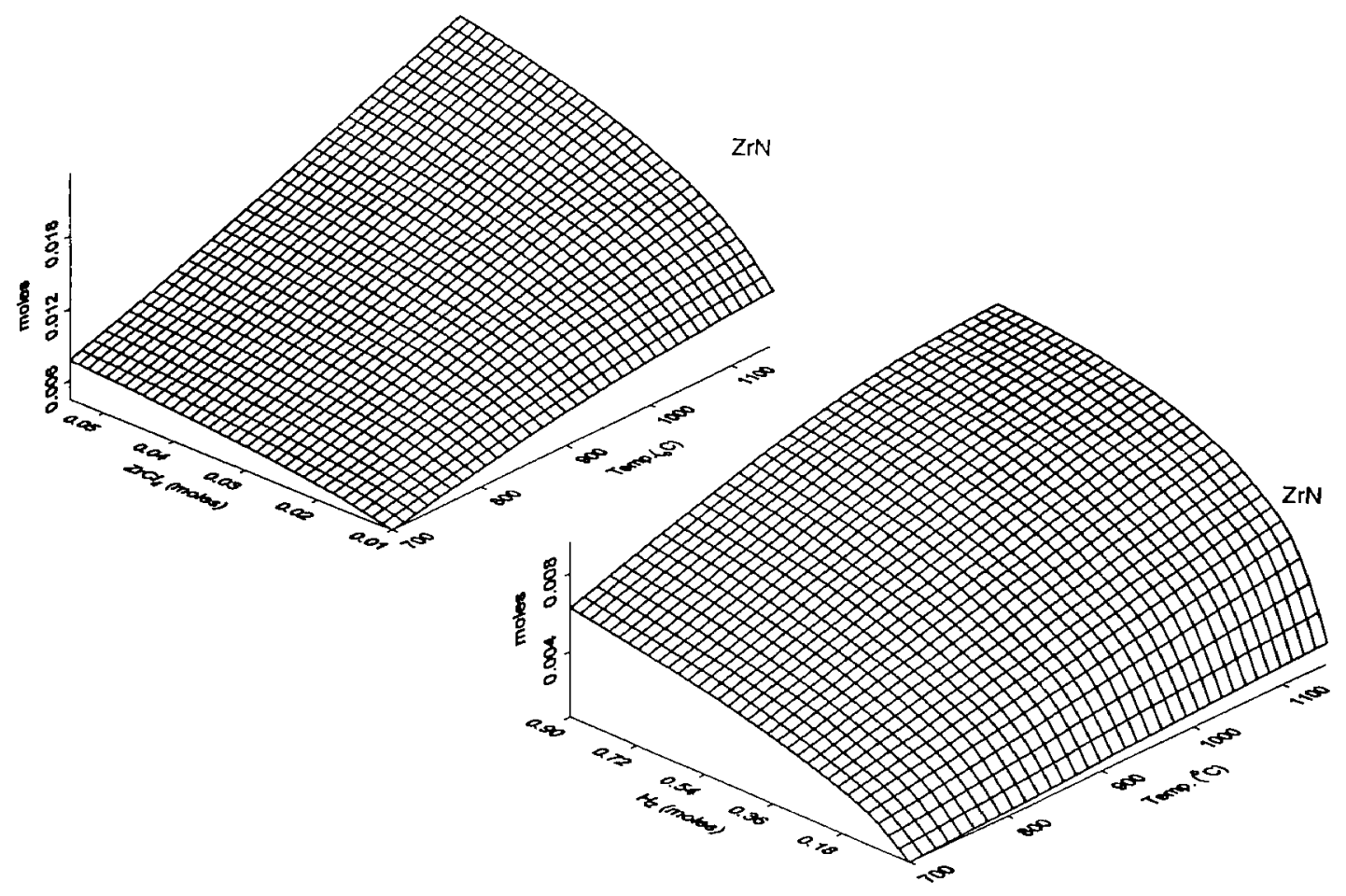

Figure 1(a) Predicted ZrN production (press. $=150$ torr, $\mathrm{N}_{2}=0.392$ mole, $\mathrm{H}_{2}=0.593$ mole) (b) (press. $=150$ torr, $\mathrm{ZrCl} \mathrm{Cl}_{4}=$ 0.014 mole, $N_{2}=0.392$ mole)

line represent an effect outside the limits of the normal probability. The graph for deposition rate is shown in Figure 2. The three $\mathrm{X}$ 's represent the original computer generated fit. The effects of $\mathrm{B}$ (temperature), $\mathrm{C}$ $\left(\mathrm{H}_{2} / \mathrm{ZrCl}_{4}\right)$ and $\mathrm{BC}$ (interaction of temperature and $\left.\mathrm{H}_{2} / \mathrm{ZrCl}_{4}\right)$ deviate from normal probability. The effect of temperature is by far the largest. Using these key variables to correct for deviations from normal distribution a model can be created to predict deposition rate. The model is reported by the program in an ANOVA (analysis of variance) report. One way to identify the accuracy of the model is by looking at the residuals. A random distribution was observed indicating the model is good. Interaction plots were generated to separate and interpret the effects of interacting variables. In the case of deposition rate this means $B$ and $C$. The plot is shown in Figure $3 a$.

The fact that the two lines are not parallel indicates that the variables are interactive. Temperature has a larger effect and the model predicts higher deposition rates at low $\mathrm{H}_{2} / \mathrm{ZrCl}_{4}$ values. This would not seem to be consistent with Figure $1 \mathrm{~b}$, however, $\mathrm{ZrCl}_{4}$ was not held constant for the tests and low $\mathrm{H}_{2} / \mathrm{ZrCl}_{4}$ was achieved partly by using high $\mathrm{ZrCl}_{4}$ flows. For low $\mathrm{H}_{2} / \mathrm{ZrCl}_{4}$ values, $\mathrm{ZrCl}_{4}$ varied between 1.5 to 3 times the amount used for high values. Figure 1a shows more $\mathrm{ZrN}$ formation as a function of higher $\mathrm{ZrCl}_{4}$ content especially at higher temperatures. Figure 4 shows $\mathrm{ZrN}$ formation as a function of temperature and high and low $\mathrm{H}_{2} / \mathrm{ZrCl}_{4}$. Comparing this with Figure 3 a reveals that the thermodynamic and statistical models are in agreement.

Graphical representations such as cube plots are useful for interpretation of the statistical model. The cube plot for deposition rate is shown in Figure $3 \mathrm{~b}$. As can be seen from the graph, pressure had a small effect on deposition rate and is predicted to have no effect. The slowest rate is found at $\mathrm{B}-, \mathrm{C}+$ while the highest is found at $\mathrm{B}+, \mathrm{C}-$. These results are similar to those that Bhat [11] found for TiN. The deposition rate of TiN was found to be most affected by temperature and the $\mathrm{H}_{2} / \mathrm{TiCl}_{4}$ ratio. 


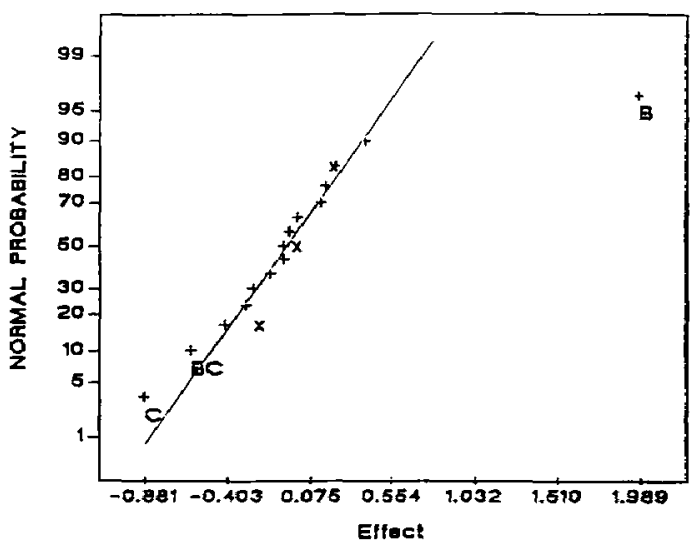

Figure 2. Probability plot for deposition rate distribution.
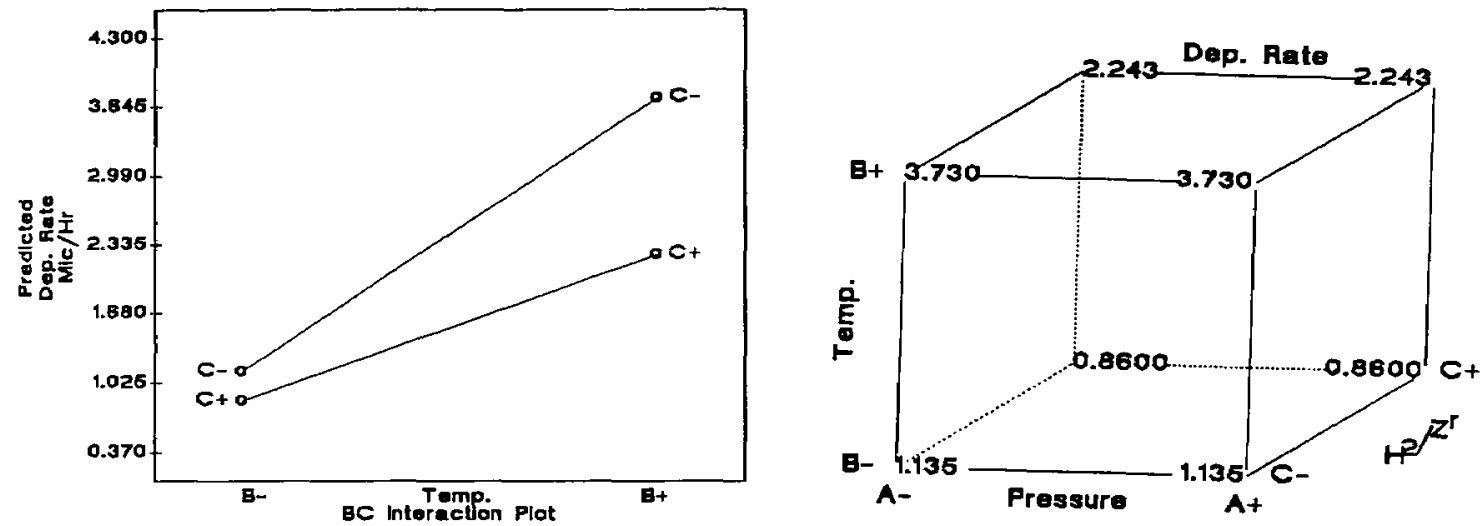

Figure 3(a) Interaction plot of temperature and $\mathrm{H}_{2} / \mathrm{ZrCl}_{4}$ effect on deposition rate, (b) cube plot of predicted values for deposition rate.

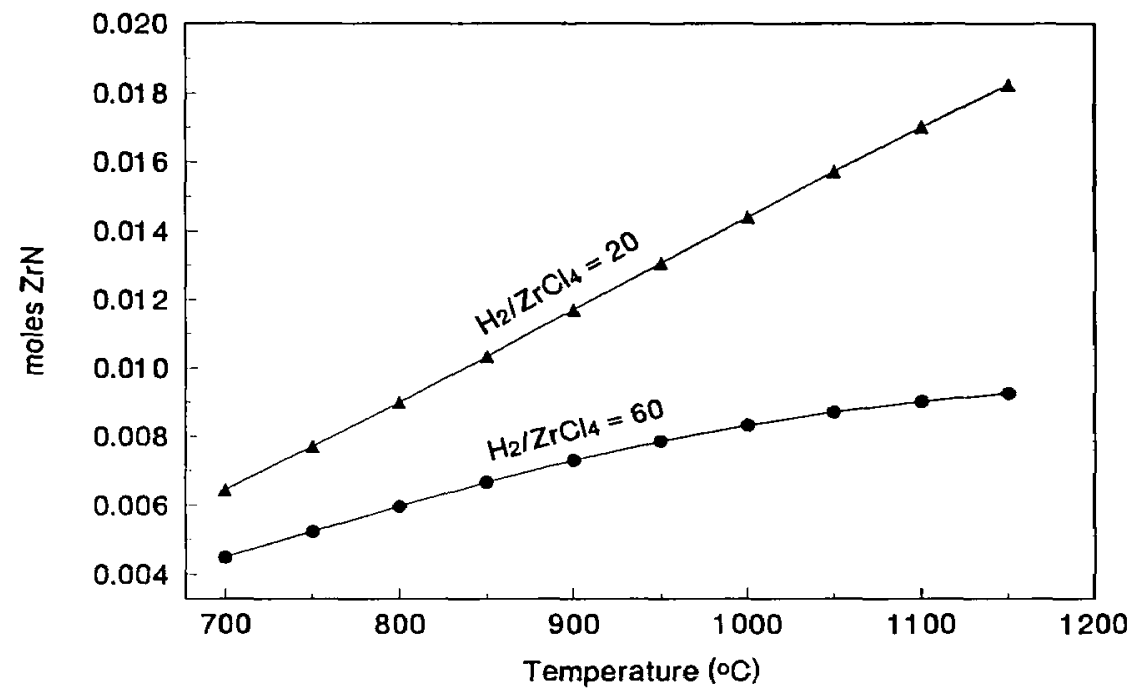

Figure 4. Thermodynamic model prediction of $\mathrm{ZrN}$ production (press. $=150$ torr, $\mathrm{N}_{2}=0.392$ mole, $\mathrm{H}_{2}=0.593$ mole). 


\subsection{Appearance (Color)}

The colorsphere, color scales of measure and results (Table II) were described in section 2. An IBAD ZrN sample $\left(L^{*}=97, a^{*}=-1.4, b^{*}=28\right)$ was used as a standard. Based on this standard the goals for color were for $\mathrm{L}^{*}$ to be as high as possible, $\mathrm{a}^{*}$ to be as low as possible and $\mathrm{b}^{*}$ to approach the target of 28 on the yellow scale. Tests that approached these conditions were $\# 4,7,18,19$ and 20 with 20 having the best overall appearance.

The normal probability distribution of the $\mathrm{L}^{*}$ data showed little deviation. Thus, a single variable does not dominate in controlling the brightness of the coating. The best coatings generally had high pressure, temperature and $\mathrm{N}_{2} / \mathrm{ZrCl}_{4}$ ratio.

The color variable $\mathrm{a}^{*}$ also showed little deviation in its probability distribution. All four variables have an effect on the red content.

For $\mathrm{b}^{*}$, the variables $\mathrm{A}, \mathrm{B}$ and $\mathrm{C}$ were identified as having possible interactive effects. The $\mathrm{b}^{*}$ residuals behaved normally indicating a good model. An interaction plot for B and C showed that with 28 as the yellow scale target, it was best approached by using higher temperatures.

\subsection{ZrN Crystallite Growth And Morphology}

As described in section 2, a qualitative assessment of surface crystallite structure had to be made and therefore statistical analysis could not be used. Three classifications of structures were observed:

(1) icosahedral thin needle-like or pyramidal crystals frequently having an apparent fivefold symmetry, columnar growth mode (Figure 5)

(2) rounded equiaxed structures with rounded facets, columnar growth

(3) fine very small equiaxed crystals, stratified growth mode

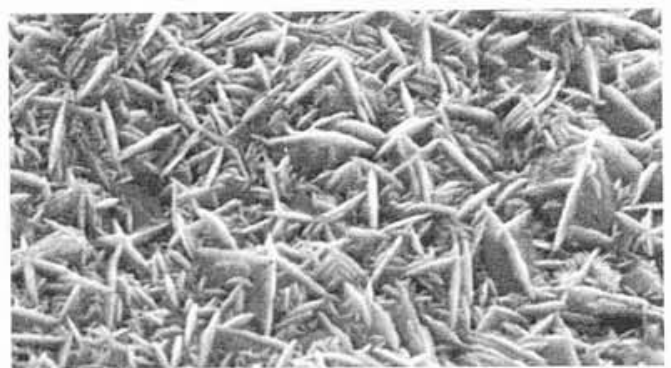

Figure 5. Icosahedral surface structure of $\mathrm{ZrN}$. (5000X)

Icosahedral structures have been previously observed in TiN coatings [11]. Table II reveals that there is a direct relationship between the occurrence of icosahedral structure and temperature. It is always present at low or medium temperatures $\left(900-975^{\circ} \mathrm{C}\right)$ but is replaced by rounded or fine structure at high temperature $\left(1050^{\circ} \mathrm{C}\right) . \mathrm{ZrN}$, like $\mathrm{TiN}$, is a face centered cubic (fcc) crystal. Icosahedral symmetry is not expected but has been found in some fcc systems and can be explained by the formation of multiple twins during growth [11-13]. Five tetrahedra are aligned around a stem in the (220) direction with a certain amount of elastic misfit strain. In TiN coatings it was found that for failure by flank wear, orientation in the (111) direction (non-icosahedral) was favorable as opposed to orientation in the (220) direction (icosahedral). Differences in packing for the crystal faces presented may account for the observed differences in wear.

\subsection{Texture Analysis}

Section 4.3 showed how deposition temperature correlated with a change in structure from icosahedral to non-icosahedral. Correlations can also be made between this phenomenon and changes in texture. Shifts 


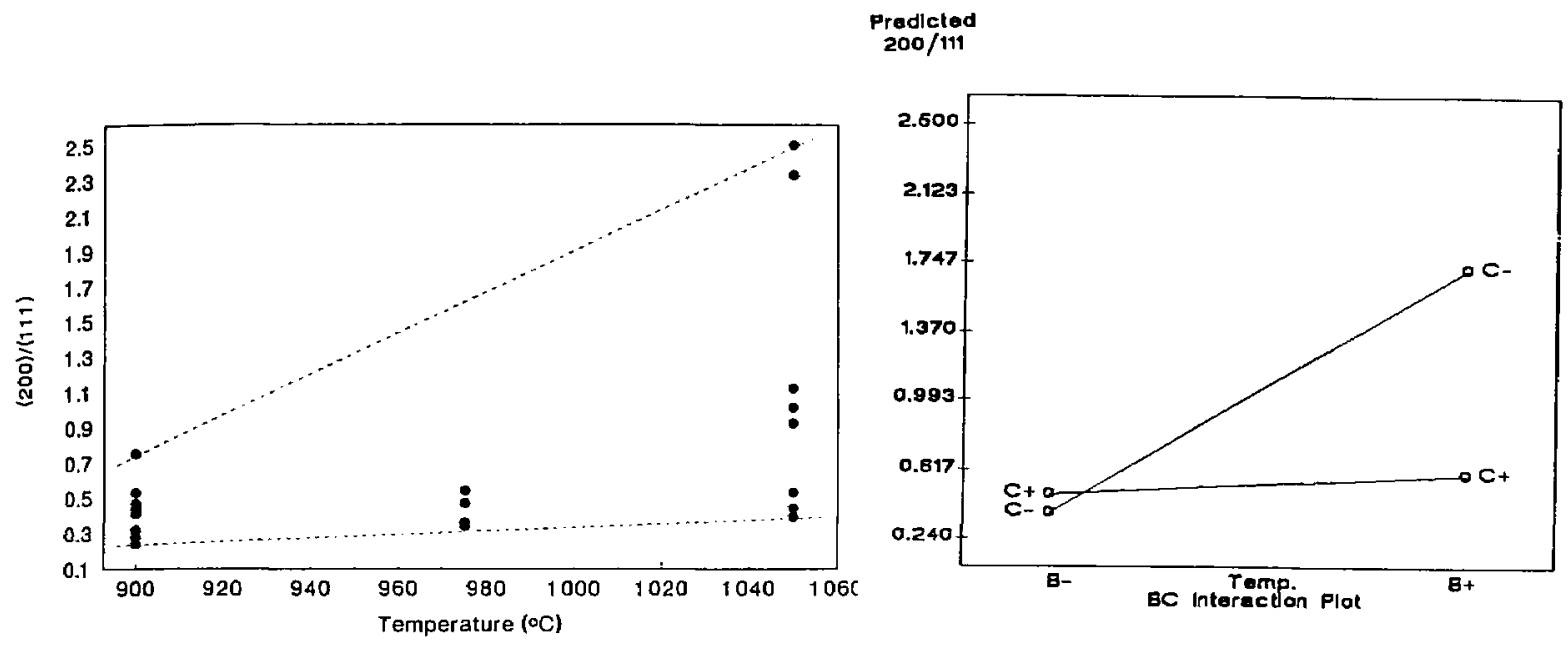

Figure 6(a) Temperature response of (200)/(111) peak ratios (b) predicted response to temperature and $\mathrm{H}_{2} / \mathrm{ZrCl}_{4}$.

in peak intensity ratios also correlate with structural shifts. Figure 6a shows how the $(200) /(111)$ peak intensity ratio shifts with temperature for the matrix experiments. This ratio increases dramatically at high temperature corresponding to the shift in structure to non-icosahedral. The same effect is seen for low values of $\mathrm{H}_{2} / \mathrm{ZrCl}_{4}$. Statistical analysis showed a strong interaction between $\mathrm{B}$ and $\mathrm{C}$ for this $(200) /(111)$ ratio (Figure 6b) and confirms the raw data trend shown in Figure 6a.

$\mathrm{TC}_{200}$ as a function of temperature has the same relationship as the peak ratios in Figure 6a. Closely grouped data are again associated with icosahedral structures at low and mid-temperatures. An increase in $\mathrm{TC}_{200}$ corresponds with a decrease in icosahedral structure.

In Bhat's paper on TiN [11] icosahedral structure stability was lost when orientation changed from (220) to (111). For $\mathrm{ZrN}$ this is the case when orientation shifts from (111) or (220) to (200). Table III shows these peak ratio shifts. There is no shift in the $(220) /(111)$ ratio with the change in structure. The shifts of $(200) /(111)$ and $(200) /(220)$ are of approximately the same magnitude.

Table III: Orientation Ratios of ZrN Structures

\begin{tabular}{|c|c|c|c|}
\hline Structure & $(\mathbf{2 0 0}) /(\mathbf{1 1 1})$ & $(\mathbf{2 2 0}) /(\mathbf{1 1 1})$ & $\mathbf{( 2 0 0 ) / ( 2 2 0 )}$ \\
\hline \hline Icosahedral & .43 & .92 & .49 \\
\hline Non-icosahedral & 1.16 & .93 & 1.45 \\
\hline
\end{tabular}

\subsection{Adhesion and Friction Testing}

Adhesion and friction were measured as described in section 2.2. During adhesion testing coating defects can contribute to the acoustic signal, however, the greatest source of signal is from interfacial fracturing of a cohesive or adhesive nature in which new surface area is formed. Scratches on $\mathrm{ZrN}$ were smooth indicating a good deal of plastic deformation and no spalling was observed indicating mainly cohesive fracturing.

The apparent friction coefficient $\left(\mu^{*}\right)$ is defined as the ratio between the tangential force $\left(F_{t}\right)$ and the normal load $\left(\mathrm{F}_{n}\right)$. A plotter connected to the Revelest ${ }^{\mathrm{TM}}$ unit can be used to graph $\mathrm{F}_{\mathrm{t}}$ directly as a function of $\mathrm{F}_{\mathrm{n}}$. The slope of this line yields $\mu^{*}$. Results for tests on TiN and $\mathrm{ZrN}$ are compiled in Table IV. 
Friction between the diamond and the coating is significantly less for $\mathrm{ZrN}$ compared to TiN. This is a very desirable coating property, especially in applications with adhesive or "gummy" workpiece materials. The friction measurements were very repeatable at the different loading rates.

Table IV: Friction Measurements for CVD ZrN and CVD TiN

\begin{tabular}{|c|c|c|c|c|c|}
\hline Coating & $\begin{array}{c}\text { Load Rate } \\
(\mathbf{N} / \mathbf{m i n})\end{array}$ & $\begin{array}{c}\mathbf{F}_{\mathbf{t}} \\
(\mathbf{N})\end{array}$ & $\begin{array}{c}\mathbf{F}_{\mathbf{n}} \\
(\mathbf{N})\end{array}$ & $\boldsymbol{\mu}^{*}$ & Avg. $\boldsymbol{\mu}^{*}$ \\
\hline \hline TiN & 100 & 12.3 & 100 & .123 & .125 \\
\hline & 75 & 9.3 & 75 & .124 & \\
\hline & 50 & 6.7 & 50 & .134 & \\
\hline & 25 & 3.0 & 25 & .120 & \\
\hline $\mathbf{Z r N}$ & 100 & 4.0 & 100 & .040 & .040 \\
\hline & 75 & 3.0 & 75 & .040 & \\
\hline & 50 & 2.0 & 50 & .040 & \\
\hline & 25 & - & 25 & -- & \\
\hline
\end{tabular}

\section{SUMMARY AND CONCLUSIONS}

Statistical methods were used to generate a test matrix of twenty experiments to study the effects of temperature, pressure and reactant gas concentrations on the CVD of ZrN. Prior to experimentation, thermodynamic modeling indicated that it was possible to produce $\mathrm{ZrN}$ over a wide range of coating conditions. Test matrix parameters were derived from this analysis. As with CVD of TiN, the deposition rate of $\mathrm{ZrN}$ was found to be most responsive to temperature and $\mathrm{H}_{2} / \mathrm{ZrCl}_{4}$ ratio. Color, as defined by a three coordinate color "space" was not sensitive to any one key coating parameter. The effects of the parameters were found to be interactive. $\mathrm{ZrN}$ morphology exhibited five-fold icosahedral symmetry for all but the high temperature deposited coatings. Texture analysis showed that structure changed from icosahedral to non-icosahedral when crystallographic growth orientation changed from (111) or (220) to (200). Despite a larger acoustic signal from $\mathrm{ZrN}$ samples compared to TiN, no spalling was observed in adhesion testing. The signal is attributed to significant plastic deformation. The friction coefficient was consistently lower for $\mathrm{ZrN}(0.040)$ compared to $\mathrm{TiN}(0.125)$.

\section{References}

[1] Koelsch, J.R., Manufacturing Engineering, October, 1992, 27-32.

[2] Netterfield, R.P., Martin, P.J. and MacKenzie, D.R., J. of Materials Science Letters, 9, 1990, 972-974.

[3] Korhonen, A.S., Molarius, J.M., Penttinen, I. and Harju, E., Materials Science and Engineering, A105/106, 1988, 497-501.

[4] Design-Ease, a product of Stat-Ease Inc., Minneapolis, Minnesota, U.S.A., 1991.

[5] Box, G.E.P., Hunter, W.G. and Hunter, J.S., Statistics For Experimenters, John Wiley \& Sons, Inc., 1978.

[6] Hintermann, H.E., Wear, 100, 1984, 381-397.

[7] Seklar, J., Steinmann, P.A. and Hintermann, H.E., Surface and Coatings Technology, 36, 1988, $519-$ 529.

[8] Roine, A., Outokumpu HSC Chemistry for Windows, Outokumpu Research Oy, Pori, Finland, 1993.

[9] Colmet, R., Naslain, R., Hagenmuller, P. and Bernard, C., J. Electrochemical Soc., 129, 1982, 13671372.

[10] Colombier, C., Lux, B. and Lindström, J., Refractories and Hard Materials, December, 1986, 222229.

[11] Bhat, D.G., Shah, D.C., Boppana, P. and Sung, C., Surface Modification Technologies VI, 1993, 671-685.

[12] Hillert, M. and Agren, J., Acta Metallurgica, 33, 1985, 1621.

[13] Cheng, D.J., Sun, W.P. and Hon, M.H., Journal of Crystal Growth, 71, 1985, 787. 